\title{
Cost Minimization Analysis of Radiofrequency Compared to Laser Thermal Ablation in Patients with Hepatocellular Carcinoma
}

Maria Guarino ${ }^{1}$, Lucia S. D'Angiolella ${ }^{2}$, Luigia Falco ${ }^{3}$, Federica Morando ${ }^{1}$, Giovan Giuseppe Di Costanzo ${ }^{3}$, Filomena Morisco ${ }^{1}$, Giovanni Improta ${ }^{4}$, Lorenzo G. Mantovani ${ }^{2}$, Nicola Caporaso ${ }^{1}$

\author{
Gastroenterology Unit, Department of Clinical Medicine and Surgery, University of Naples "Federico II", Naples, Italy \\ Research Centre on Public Health (CESP), University of Milan Bicocca, Monza, Italy \\ Hepatology Unit, AORN Cardarelli, Naples, Italy \\ Department of Public Health, University of Federico II', Naples, Italy
}

\begin{abstract}
BACKGROUND: Over the last decade of years, minimally invasive techniques have been developed for the treatment of hepatocellular carcinoma and liver metastases. We sought to investigate the health costs associated with the management of patients with hepatocellular carcinoma treated with radiofrequency vs laser thermal ablation and their clinical outcomes. METHODS: We performed a retrospective analysis of the ablations performed in two referral centers in southern Italy, from 2009 to 2013. Resource use was valued by year 2017 official prices, in $€$. Direct healthcare costs (drugs, visits, tests and hospitalizations) of different ablation techniques were compared. Total costs were analyzed from Italian NHS perspective. RESULTS: A total of 140 patients were identified. Baseline demographics and clinical outcomes of interest did not differ between the two groups. Patients treated with laser thermal ablation resulted in an expected annually cost savings of 258.9 $€$ per patient, in one-year follow-up healthcare costs compared with radiofrequency. The largest components of annual medical expenditures were attributable to drugs, regardless of the type of ablative technique.

CONCLUSIONS: The ablation using either laser thermal ablation or radiofrequency is equally effective. Laser thermal ablation would carry disposable cost savings as compared to radiofrequency. The costs associated with management of patients with hepatocellular carcinoma, treated with laser thermal ablation were lower than those treated with radiofrequency ablation.
\end{abstract}

\section{Keywords}

Hepatocellular carcinoma; Laser ablation; Radiofrequency; Pharmacoeconomic analysis

\section{INTRODUCTION}

Hepatocellular carcinoma (HCC) is a global health problem and constitutes the main cause of death among cirrhotic patients $[1,2]$. The best treatment option is liver transplantation, which is, however, difficult to implement for lack of donors. So surgical resection represents the first choice treatment, but it is not always feasible due to tumor size, number of nodules, location, comorbidities, and the progressive deterioration of liver function in patients with cirrhosis [2]. Percutaneous ablation represents the most widely used treatment for patients at early stage who are not suitable to surgery or liver transplantation [3]. Over the years, several techniques for loco-regional ablation have been developed for the treatment of HCC. In particular, several thermal ablative procedures have been developed for the treatment of HCC, like Laser Thermal Ablation (LTA) and Radiofrequency Ablation (RF). The thermal ablative techniques have gained an increasing role due to their efficacy in terms of avoided local recurrence and prolonged Overall Survival (OS) [4]. Furthermore, these therapies destroy only a small part of liver parenchyma and reduce the surgical complications [5]. RF ablation is undoubtedly the most widely employed and studied technique [6]; the radiofrequency-generated heat for ionic agitation devastates the tumoral tissue [7]. However, this mechanism of action could decrease the efficacy of the procedure [8]. LTA has recently undergone significant dif-

Corresponding author Lucia S. D'Angiolella I.dangiolella@campus.unimib.it

Received: 10 January 2019 Accepted: 29 March 2019 Published:19 April 2019 
fusion, although less investigated than RF: several retrospective and prospective studies have shown that LTA is a safe, feasible and effective procedure for the treatment of HCC [9-13]. LTA uses the interaction between light energy and tissue. It damages the tumoral tissue with a thermal destruction due to light converted to heat [14]. Some evidence from literature showed no difference regarding efficacy between LTA and RF [13], therefore, in absence of clear clinical benefit it may be interesting to focus on the resource use associated with the available techniques. Regardless of the benefits, LTA and RF lead to substantial financial implications. However, a comprehensive picture of the clinical and economic impact of HCC patients, undergoing RF or LTA is still lacking. This analysis aimed to estimate the efficacy and one-year follow-up healthcare costs of RF and LTA in patients with HCC.

\section{METHODS \\ Patients}

From January 2009 to September 2013, adult patients with a new diagnosis of HCC treated with RF or LTA were recruited in two referral centres in southern Italy (the Gastroenterology Unit of the University of Naples "Federico II" and the Liver Unit of the "A. Cardarelli" Hospital of Naples). The analysis was performed in accordance with the principles of the Declaration of Helsinki and its appendices. During data collection process, the information was already available in hospital records. Data were analyzed with a unique and anonymous personal identification code. Therefore, neither ethical committee approval nor informed consent forms were required. The analysis was a retrospective, observational series. Inclusion criteria were as follows: 1) new diagnosis of HCC; 2) naïve to treatment; 3) age 18 years or older; 4) at least 1 year of follow-up. Demographic characteristics and clinical parameters at baseline, including age, sex, Body Mass Index (BMI), aetiology of liver disease, presence of cirrhosis, presence of portal hypertension, Child-Pugh-Turcotte (CPT) class, Model For EndStage Liver Disease (MELD) score, gross pathology, extrahepatic diffusion of HCC, presence of portal vein thrombosis, biochemistry parameters and presence of comorbidities, were recorded. The diagnosis of HCC was performed according to the European Guidelines of the European Association For The Study Of The Liver (EASL) [2] and staged by imaging technique workup: dynamic Computer Tomography (CT), Contrast-Enhanced Ultrasonography (CEUS), dynamic Magnetic Resonance Imaging (MRI), thereafter combining the diagnostic Alpha-Fetoprotein (AFP) increase $(>200 \mathrm{ng} / \mathrm{ml})$. Number and size of nodules, vascular invasion and extra-hepatic spread were evaluated.

\section{Treatment choice}

Treatment options were considered according to the Barcelona Clinic Liver Cancer (BCLC) staging system, its update and the recommendations released by the Italian Association for the Study of the Liver (AISF) [15-17]. Treatment decisions were taken by a multidisciplinary liver tumor Committee, and were influenced by several factors, including comorbidities, specific contraindications for each procedure, local transplant criteria, patient's opinion and physician judgement. The RF or LTA procedure was subsequently decided, once the surgical curative treatment or radiologic intervention had been ruled out. Both procedures were performed percutaneously under conscious sedation and ultrasound guidance. Other details about two techniques are reported in Table I. Only operators with $>5$ years of experience in percutaneous ablations were admitted. Before percutaneous procedures, patients were hospitalized for 2 days unless complications occurred.

\section{Assessment of treatment effectiveness and follow-up}

All patients were followed-up for one year since the performance of each treatment with clinical, laboratoristic and imaging evaluation (ultrasonography, CT or MRI) performed at

\begin{tabular}{lcc}
\hline \multicolumn{1}{c}{ Parameter } & RF & LTA \\
\hline Carriage & Single electrode & Laser fibers \\
Ablation time & $10-12$ minutes [13] & $4-6$ minutes [13] \\
Needle size & $17-G$ [13] & $21-G$ [13] \\
$\begin{array}{l}\text { Mechanism } \\
\text { of action }\end{array}$ & $\begin{array}{l}\text { Joule effect (heating of } \\
\text { tissues via ionic vibrations) }\end{array}$ & $\begin{array}{c}\text { High-frequency thermic } \\
\text { coagulation }\end{array}$ \\
\hline
\end{tabular}

Table I. Comparison between radiofrequency (RF) and laser thermal ablation (LTA) techniques intervals of 4-12 weeks in relation to HCC stage and clinical needs of the single patient. Response to therapy was evaluated with imaging techniques performed one, three, six and twelve months after treatment, according to the Modified Response Evaluation Criteria in Solid Tumors (mRECIST) criteria [18]. Based on the imaging results, tumor ablation and thus response to treatment were defined as complete when there was disappearance of all signs of lesion and no patho- 
logical enhancement was detectable on the edges of the treated area. Ablation was considered partial or incomplete in the case of a partial destruction of the lesion, with a reduction of at least $30 \%$ of the volume; in the case of incomplete ablation, a second treatment was carried out during the following 2 weeks. The medium-term results were assessed according to local progression of disease, meaning the presence of enhancement in proximity to the ablation site and the onset of new lesions at a distance.

\section{Complications}

According to the classification of the International Society of Radiology [19], complications were defined major if substantial morbidity, disability, care, hospitalization with a prolonged hospital stay occurred. Otherwise, complications were defined as minor. Other events was investigated during the first $48 \mathrm{~h}$ after treatment.

\section{Statistical analysis}

The demographic and clinical patients' characteristics and costs related to different surgery options was collected. Descriptive statistical analysis of the involved patient for all categories were described with means as the central tendency parameter and minimum and maximum values as dispersion parameters. A regression analysis was also performed to control for potential confounders. The choice of these confounding variables was made according to knowledge of clinical expert. For all statistical comparisons, a level of p-value $<0.05$ was accepted as statistically significant. All statistical analyses were performed using R software/ environment.

\section{Pharmacoeconomic analysis}

Healthcare costs were analysed from the perspective of the Italian NHS. Four main cost categories related to the management of patients with HCC were identified: monitoring test, procedure attributable to the disease and surgical techniques, visit and drug. For analysis of costs, means (minimum-maximum) were used as central tendency parameter, expressed as

\begin{tabular}{|c|c|c|c|}
\hline & $\operatorname{LTA}(n .=70)$ & $\operatorname{RF}(n .=70)$ & p-value \\
\hline Age, years mean $\pm S D$ & $73.6 \pm 9.2$ & $73.5 \pm 7.9$ & 0.621 \\
\hline Male, n. (\%) & $47(67.1)$ & $54(77.1)$ & 0.187 \\
\hline Cirrhosis, n. (\%) & $64(91.4)$ & $63(90.0)$ & 0.771 \\
\hline \multicolumn{4}{|l|}{ Liver disease etiology, n. (\%) } \\
\hline - HCV infection & $58(82.9)$ & $50(71.4)$ & 0.107 \\
\hline - HBV infection & $8(11.4)$ & $13(18.6)$ & 0.237 \\
\hline - Others & $4(5.7)$ & $7(10.0)$ & 0.215 \\
\hline Presence of diabetes, n. (\%) & $20(28.6)$ & $20(28.6)$ & 1.000 \\
\hline \multicolumn{4}{|l|}{ Child-Pugh Class, n. (\%) ${ }^{1}$} \\
\hline - A & $64(91.4)$ & $65(92.8)$ & 0.753 \\
\hline - B & $5(7.1)$ & $4(5.7)$ & 0.730 \\
\hline$\cdot \mathrm{C}$ & - & - & - \\
\hline MELD score < 10, n. (\%) & $49(70.0)$ & $47(67.1)$ & 0.716 \\
\hline Diagnosis on surveillance, n. (\%) & $45(64.3)$ & $29(41.4)$ & 0.007 \\
\hline \multicolumn{4}{|l|}{ HCC morphology, n. (\%) } \\
\hline - Single nodule & $59(84.3)$ & $60(85.7)$ & 0.8129 \\
\hline - Multinodular & $11(15.7)$ & $10(14.3)$ & \\
\hline Largest nodule size, $\mathrm{mm}$ mean $\pm \mathrm{SD}$ & $28.34 \pm 9.6$ & $25.56 \pm 6.5$ & 0.1361 \\
\hline \multicolumn{4}{|l|}{ BCLC Class, n. (\%) } \\
\hline - A & $64(91.4)$ & $58(82.9)$ & \\
\hline • B & $6(8.6)$ & $12(17.1)$ & 1200 \\
\hline - $\mathrm{C}$ & - & - & 0.1298 \\
\hline . D & - & - & \\
\hline
\end{tabular}

Table II. Baseline characteristics of patients

1 2/140 patient data not available

BCLC: Barcelona Clinic Liver Cancer; HBV: Hepatitis B virus; HCC: Hepatocellular Carcinoma; HCV: Hepatitis C virus; LTA: Laser Thermal Ablation; MELD: Model For End-Stage Liver Disease; RF: Radiofrequency; SD Standard Deviation 
mean cost per patient per year. To concert these data to monetary terms, we multiplied the amount of resources consumed. The calculation is:

Fixed unit cost * Number of annual units $=$ Total cost

Their unit cost derived from tariffs or prices applicable in Italy in 2017. In particular, medical costs were quantified using prices tariffs paid by the NHS: the Italian Drug Agency price list was used for drug costs [20]. Costs for outpatient services were obtained from national tariffs [21]. Consumption of resources related with direct costs was expressed as the frequency of cost items occurring in the different subgroup of patients.

\section{RESULTS}

\section{Sample description}

From January 2009 to September 2013, 140 consecutive patients with a diagnosis of HCC were recruited and treated. Baseline characteristics of the enrolled patients are detailed in Table II. Demographics, clinical and disease-stage characteristics were comparable between the two groups. The mean age of our populations was 73 years (range $44-90$ years), two/third of them were males and more than $90 \%$ of them had a cirrhosis. The main cause of the liver disease was Hepatitis C Virus (HCV) infection. Most of them showed a well-compensated liver disease (more than 90\%) and an early stage HCC with only one nodule. The mean nodule diameter was $27.14 \mathrm{~mm}$; however, the nodule diameter was smaller than $20 \mathrm{~mm}$ in 43 patients $(30.7 \%)$, between $21-50 \mathrm{~mm}$ in 96 patients $(68.6 \%)$, and larger than $50 \mathrm{~mm}$ only in 1 patient $(7.1 \%)$.

\section{Treatment analysis}

Treatment analysis results of the two techniques are detailed in Table III. Patients were treated to either RF ( 70 patients, with a total of 81 nodules) or LTA ( 70 patients, with a total of 81 nodules). For treating each nodule, one RF needle/nodule and a mean of 3.8 LTA fibers/ nodule were used. No procedure was interrupted in each group. None of the patients in both groups showed intra- and post-procedural complications. The mean hospital stay was similar in the two groups with a mean value of 1.7 days per patient. According to the mRECIST criteria, a complete response was obtained and maintained at $12^{\text {th }}$ month in $65.7 \%$ of lesions treated with RF and $55.7 \%$ of those treated with LTA. The HCC recurrence within one year after treatment was observed in $40.0 \%$ of LTA patients and in $32.9 \%$ of RF ones, after a mean time of 9 months in both groups. The one year mortality rate was similar in both groups $(1.4 \%$ LTA vs $2.1 \%$ RF). Not statistically significant differences were obtained in measured outcomes. Overall, the efficacy was comparable between the two techniques.

\section{Cost analysis}

A Cost Minimization Analysis (CMA) was performed to compare the costs of two equally effective competing treatment strategies, since they have comparable clinical outcomes. Oneyear follow-up healthcare costs were slightly higher for RF compared to LTA (Table IV). The

\begin{tabular}{lccc}
\hline & LTA & RF & p-value \\
\hline Patients treated, $\mathrm{n}$. & 70 & 70 & \\
Nodules treated, $\mathrm{n}$. & 81 & 81 & \\
Overall needles/devices used & 3.8 fibers & 1.0 needle & \\
$\begin{array}{l}\text { Adverse events to procedure, } \mathrm{n} . \\
\text { Hospital stay, days mean (SD) }\end{array}$ & 0 & 0 & \\
$\begin{array}{l}\text { Patients with complete response } \\
\text { at 12th month, n. (\%) }\end{array}$ & $39(55.7)$ & $46(65.7)$ & 0.226 \\
$\begin{array}{l}\text { Nodules with complete response } \\
\text { at 12th month, n. (\%) }\end{array}$ & $41(58.6)$ & $53(75.7)$ & 0.349 \\
$\begin{array}{l}\text { Patients with 1 year recurrence } \\
\text { rate, n. (\%) }\end{array}$ & $28(40.0)$ & $23(32.9)$ & 0.379 \\
$\begin{array}{l}\text { Mean time to recurrence, months } \\
\text { 1-year mortality rate, \% }\end{array}$ & 9.0 & 9.3 & 0.367 \\
\hline
\end{tabular}

Table III. Treatments characteristics

LTA: Laser Thermal Ablation; RF: Radiofrequency; SD: Standard Deviation expected costs for a patient who underwent ablation of HCC with RF, within one year totaled $€ 1,209.0$. Patients who underwent LTA incurred the lower costs $(€ 949.9)(\mathrm{p}<0.341)$. A positive trend towards one-year follow-up healthcare costs was observed for patients treated with LTA, compared with RF (Figure $1 \mathrm{~A}$ ), although the difference in values was not statistically significant: the mean difference resulted in an expected annually cost savings was $€ 258.9$ per patient treated with LTA, compared with RF. The largest components of annual medical expenditures for patients treated with RF are drugs $(46.7 \%)$, procedures $(40.2 \%)$, monitoring tests $(10.4 \%)$ and visits $(2.7 \%)$. For patient treated with LTA, the main cost item was procedures $(55.5 \%)$, followed by drugs $(21.1 \%)$, monitoring tests $(13.2 \%)$ and visits (13.2\%) (Figure 1B). 
Presence of cirrhosis, Child-Pugh score and Meld score were selected as variables potentially related with total direct costs. Figure 2 shows the one year follow-up healthcare costs estimated in each group of patients. The cost management of patients treated with LTA resulted the least costly treatment, compared to RF. Patients without cirrhosis, on average,

\begin{tabular}{lllc}
\hline \multicolumn{1}{c}{$\begin{array}{c}\text { Cost item, mean } \\
\text { (min-max) }\end{array}$} & \multicolumn{1}{c}{ Cost $(\boldsymbol{\epsilon})$} & \multicolumn{1}{c}{ LTA } & p-value \\
\cline { 2 - 4 } & \multicolumn{1}{c}{ RF } & \multicolumn{1}{c}{ LTA } & 0.950 \\
\hline Monitoring tests & $125.7(80.46-268.20)$ & $125.29(26.82-268.20)$ & 0.030 \\
Procedures & $485.51(218.50-842.50)$ & $527.01(158.00-840.30)$ & 0.495 \\
Visits & $33.30(0.00-2,091.00)$ & $96.88(0.00-6,162.00)$ & 0.916 \\
Drugs & $564.24(7.48-13,090.00)$ & $200.73(7.48-1,672.00)$ & 0.341 \\
Total & $1209.00(454.50-13,440.00)$ & $949.91(502.80-6,793.00)$ & \\
\hline
\end{tabular}

Table IV. One-year follow-up healthcare costs

LTA: Laser Thermal Ablation; RF: Radiofrequency

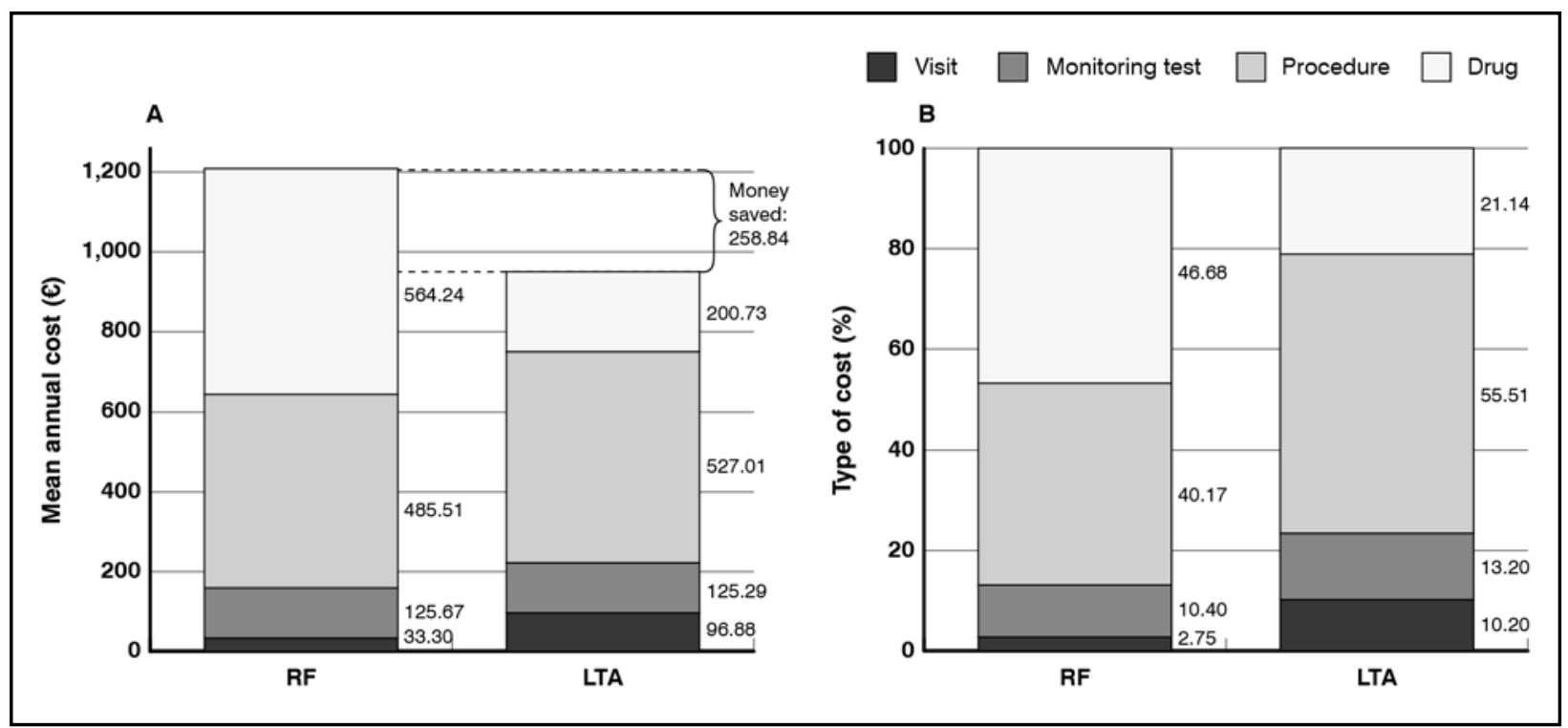

Figure 1. Differential cost analysis (A) and resources' type (B) LTA: Laser Thermal Ablation; RF: Radiofrequency

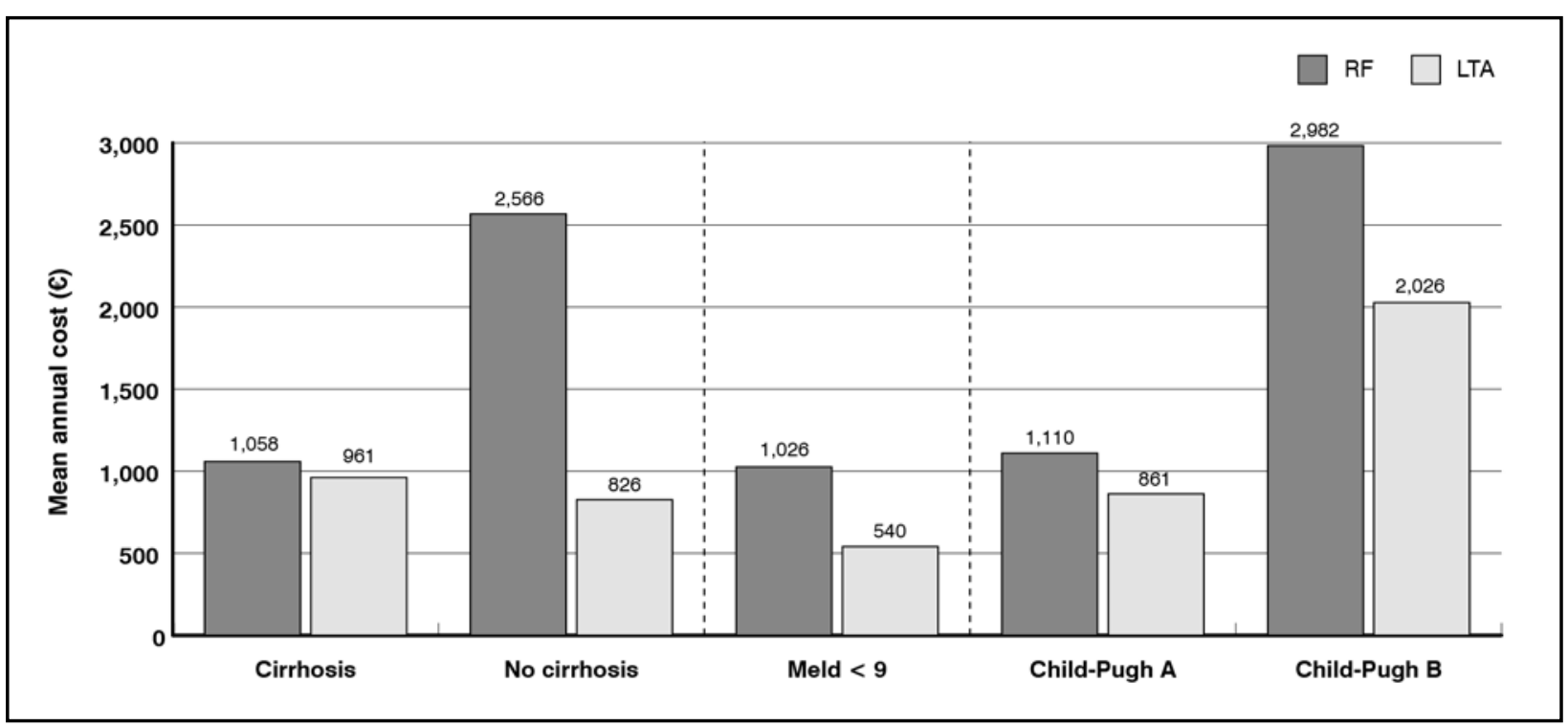

Figure 2. Direct costs in selected patients' subgroup

LTA: Laser Thermal Ablation; MELD: Model For End-Stage Liver Disease; RF: Radiofrequency 
reported one year follow-up healthcare costs for LTA approximately three times lower than what expenditures would be after RF. From the regression model, no variables were significantly related to costs.

\section{DISCUSSION}

HCC affected up to a million people per year worldwide [22]. New techniques are currently available in the treatment of $\mathrm{HCC}$ but solid evidences concerning their effectiveness and their pharmacoeconomic aspects have yet to be clarified. The objective of this analysis was to estimate the efficacy of RF and LTA and the one year follow-up costs of patients treated with either of two techniques. According with literature, our analysis found LTA and $\mathrm{RF}$ to be equally effective $[4,8,22]$. Given the equivalent outcome, the CMA was used to analyze the one year follow-up healthcare costs of patients treated with RF and LTA. The costs of management of patient post discharge may offer additional insight into decision making, given that economic evaluations about RF and LTA, in HCC are scarce. Di Costanzo et al. [13] reported only the price of the devices and concluded that LTA resulted cheaper than RF ( $€ 90,000$ vs. $€ 144,000$ ). The wide range variation in the costs could be attributed to number of devices and needles used. In France, Tapper et al. [23] estimated the cost of reimbursement paid to hospitals, under the French perspective Payment System. Based on setting used, the cost of RF in patients with HCC and HCV ranged from $€ 1,585$ to $€ 12,967$, for surgery performed in outpatient setting and in inpatient setting, respectively. However, in Italy no differences were reported for inpatient reimbursement, between patient with HCC treated with RF or LTA. Therefore, our analysis reported the cost of patients treated with RF or LTA, during one year of follow-up and defined the LTA as the cheapest alternative, regarding the management of patient. The increase of procedure cost in patients treated previously with LTA, was partially offset by the decrease in other costs.

This analysis has some potential limitations. First, the sample size is relatively small and therefore solid conclusions about the efficacy of RF and LTA cannot be done. The results may not be generalizable to patients with HCC in other centers or Countries, therefore they will need to be externally confirmed. According with perspective adopted, indirect costs were not included in the analysis. Another limitation is the relatively short follow-up time, which could preclude an evaluation of longer-term outcomes. However, this is the first analysis that estimates the efficacy of LTA and RF for treatment of HCC and costs associated with management of these patients. Future researches on patients with HCC treated with the most recent ablative techniques should be aim to provide a real estimation of resource use reported by the patients, and to associate this impact with the different characteristics over long-term horizon.

\section{CONCLUSIONS}

The study showed similar efficacy between LTA and RF for the treatment of patients with HCC. However, the pharmacoeconomic analysis suggested that LTA could be a less costly alternative, compared with RF. This paper could provide some suggestions for future analyses. Comparative pharmacoeconomic studies in addition to clinical evidences are needed for more efficient use of resources in the management of patients with HCC.

\section{Funding}

This article has been published without the support of sponsors.

\section{Conflicts of Interests}

The authors declare they have not competing financial interests concerning the topics of this article.

\section{REFERENCES}

1. Forner A, Llovet JM, Bruix J. Hepatocellular carcinoma. Lancet 2012; 379: 1245-55; https:// doi.org/10.1016/S0140-6736(11)61347-0

2. European Association For The Study Of The Liver; European Organisation For Research And Treatment Of Cancer. EASL-EORTC clinical practice guidelines: management of hepatocellular carcinoma. J Hepatol 2012; 56: 908-43; https://doi.org/10.1016/j.jhep.2011.12.001 
3. Facciorusso A, Serviddio G, Muscatiello N. Local ablative treatments for hepatocellular carcinoma: An updated review. World J Gastrointest Pharmacol Ther 2016; 7: 477-9; https:// doi.org/10.4292/wjgpt.v7.i4.477

4. Orlacchio A, Bolacchi F, Chegai F, et al. Comparative evaluation of percutaneous laser and radiofrequency ablation in patients with HCC smaller than $4 \mathrm{~cm}$. Radiol Med 2014; 119: 298-308; https://doi.org/10.1007/s11547-013-0339-y

5. Llovet JM, Mas X, Aponte JJ, et al. Cost effectiveness of adjuvant therapy for hepatocellular carcinoma during the waiting list for liver transplantation. Gut 2002;50: 123-8

6. Kudo M. Radiofrequency ablation for hepatocellular carcinoma: updated review in 2010. Oncology 2010; 78 Suppl 1: 113-24; https://doi.org/10.1159/000315239

7. Tatli S, Tapan U, Morrison PR, et al. Radiofrequency ablation: technique and clinical applications. Diagn Interv Radiol 2012; 18: 508-16; https://doi.org/10.4261/1305-3825. DIR.5168-11.1

8. Jacobs A. Radiofrequency Ablation for Liver Cancer. Radiol Technol 2015; 86: 645-64

9. Pacella CM, Francica G, Di Lascio FM, et al. Long-term outcome of cirrhotic patients with early hepatocellular carcinoma treated with ultrasound-guided percutaneous laser ablation: a retrospective analysis. J Clin Oncol 2009; 27: 2615-21; https://doi.org/10.1200/ JCO.2008.19.0082

10. Pompili M, Pacella CM, Francica G, et al. Percutaneous laser ablation of hepatocellular carcinoma in patients with liver cirrhosis awaiting liver transplantation. Eur J Radiol 2010; 74: e6-e11; https://doi.org/10.1016/j.ejrad.2009.03.012

11. Di Costanzo GG, D'Adamo G, Tortora R, et al. A novel needle guide system to perform percutaneous laser ablation of liver tumors using the multifiber technique. Acta Radiol 2013; 54: 876-81; https://doi.org/10.1177/0284185113489825

12. Di Costanzo GG, Francica G, Pacella CM. Laser ablation for small hepatocellular carcinoma: State of the art and future perspectives. World J Hepatol 2014; 6: 704-15; https:// doi.org/10.4254/wjh.v6.i10.704

13. Di Costanzo GG, Tortora R, D'Adamo G, et al. Radiofrequency ablation versus laser ablation for the treatment of small hepatocellular carcinoma in cirrhosis: a randomized trial. $J$ Gastroenterol Hepatol 2015; 30: 559-65; https://doi.org/10.1111/jgh.12791

14. Nikfarjam M, Muralidharan V, Malcontenti-Wilson C, et al. Progressive microvascular injury in liver and colorectal liver metastases following laser induced focal hyperthermia therapy. Lasers Surg Med 2005; 37: 64-73; https://doi.org/10.1002/lsm.20194

15. Llovet JM, Bru C, Bruix J. Prognosis of hepatocellular carcinoma: the BCLC staging classification. Semin Liver Dis 1999; 19: 329-38; https://doi.org/10.1055/s-2007-1007122

16. Forner A, Reig ME, de Lope CR, et al. Current strategy for staging and treatment: the BCLC update and future prospects. Semin Liver Dis 2010; 30: 61-74; https://doi. org $/ 10.1055 / \mathrm{s}-0030-1247133$

17. Italian Association for the Study of the Liver (AISF); AISF Expert Panel; AISF Coordinating Committee, Bolondi L, Cillo U, Colombo M, et al. Position paper of the Italian Association for the Study of the Liver (AISF): the multidisciplinary clinical approach to hepatocellular carcinoma. Dig Liver Dis 2013; 45: 712-23; https://doi.org/10.1016/j.dld.2013.01.012

18. Lencioni R, Llovet JM. Modified RECIST (mRECIST) assessment for hepatocellular carcinoma. Semin Liver Dis 2010; 30: 52-60; https://doi.org/10.1055/s-0030-1247132

19. Goldberg SN, Grassi CJ, Cardella JF, et al.; Society of Interventional Radiology Technology Assessment Committee and the International Working Group on Image-guided Tumor Ablation. Image-guided tumor ablation: standardization of terminology and reporting criteria. $J$ Vasc Interv Radiol 2009; 20(7Suppl): S377-90; https://doi.org/10.1016/j.jvir.2009.04.011

20. Agenzia Italiana del Farmaco Available at http://www.agenziafarmaco.gov.it/ (last accessed: March 2015)

21. Ministero della Salute. Remunerazione prestazioni di assistenza ospedaliera per acuti, assistenza ospedaliera di riabilitazione e di lungodegenza post acuzie e di assistenza specialistica ambulatoriale. G.U. n. 23 del 28 Gennaio 2013 
22. Ferrari FS, Megliola A, Scorzelli A, et al. Treatment of small HCC through radiofrequency ablation and laser ablation. Comparison of techniques and long-term results. Radiol Med 2007; 112: 377-93; https://doi.org/10.1007/s11547-007-0148-2

23. Tapper EB, Catana AM, Sethi N, et al. Direct costs of care for hepatocellular carcinoma in patients with hepatitis C cirrhosis. Cancer 2016; 122: 852-8; https://doi.org/10.1002/ cncr. 29855 